Lexical idiomaticity and word processing. António Fábregas, Elena Felíu, Josefa Martin García, José Pazó (ed.) 2012, Los limites de la morfología. Estudios oferecidos a Soledad Varela Ortega. Madrid, Universidad Autónoma de Madrid (col. Estudios 147): 397-412.

\title{
Lexical idiomaticity and word processing
}

\section{Graça Rio-Torto}

(University of Coimbra, CELGA)

\section{Introduction}

During the post-bloomfieldian era, the lexicon is seen as the place of irregularity and idiomaticity. Compounds are often associated with idiomaticity. Idiomaticity emerges when the global meaning of the whole cannot be compositionally computed taking into account the meanings of the parts. Than, idiomaticity is in the opposite pole to compositionality.

Neuroscientific research (Ullman et al. 1997, Ullman 2001, 2004) gives support to this dichotomous approach of the irregular and the regular forms. The 'dual-route' processing model of complex words (Vannest, Polk and Lewis 2005) highlights that holistic perception of opaque and irregular structures is supported by the declarative brain system, and computational or decompositional perception is supported by the procedural brain system.

Nevertheless, a continuum between idiomaticity and compositionality grounds other theoretical approaches. In the "Parallel Architecture" (Jackendoff 1997, 2002), the lexicon and the grammar are no more clear cut domains, and their interaction is held by interface and dynamic procedures. Functional neuroimaging studies (Binder et al. 2009, among others) give support to a multimodal network of semantic brain processing. 
Lexical idiomaticity and word processing. António Fábregas, Elena Felíu, Josefa Martin García, José Pazó (ed.) 2012, Los limites de la morfología. Estudios oferecidos a Soledad Varela Ortega. Madrid, Universidad Autónoma de Madrid (col. Estudios 147): 397-412.

In this paper we explore the interaction between idiomaticity and compositionality. It is generally accepted that compositional and expectable meanings can be linearly computable. But when several readings are possible, how is the selection of each conventional one governed? What kind of mental devices support the compositional and the non literal interpretation of a complex word? When a complex word is semantically idiomatic, but morphologically decomposable, can the speaker capture the core computable meaning of the whole?

A new approach on the relation between (un) expected meanings of complex words is proposed here, in articulation with a new insight into idiomaticity. Following Rodrigues \& Rio-Torto (to appear), when they emphasize the relevance of constituents' Lexical Conceptual Structure, if conceived within a maximal semantic frame, in the processing of regular and of unexpected meanings of the whole, we claim that there is autonomous and unpredictable semantic idiomaticity regarding the compositional semantics of a complex unit, and that there is also semantic idiomaticity whose motivation is partially explainable and/or predictable (Rio-Torto 1998, Rio-Torto \& Ribeiro 2009), if based on the "maximal semantic frame" of the units involved and on the principle of "maximal semantic conciliability" (Jackendoff 2009).

The structure of this paper is the following: section 2. presents an introduction to the processing of the (non) regularities. Section 3. is an overview on the relationship between compositionality and idiomaticity. Section 4 . describes some sources and/or effects of idiomaticity. Section 5. presents final conclusions and proposals.

\section{Neuropsychological approaches about the (non) regularities}


Lexical idiomaticity and word processing. António Fábregas, Elena Felíu, Josefa Martin García, José Pazó (ed.) 2012, Los limites de la morfología. Estudios oferecidos a Soledad Varela Ortega. Madrid, Universidad Autónoma de Madrid (col. Estudios 147): 397-412.

The mental lexicon is conceived as «a repository of stored information, including all idiosyncratic, word-specific information»(Ullman 2001: 717) and the grammar contains the regularities that can be constructed online through productive rules.

Neurolinguistic studies on inflected and derived words stress the antinomy between the lexicon/the irregular $v s$ the grammar. Lexical knowledge depends on the declarative memory system and grammar depends on the procedural memory system. When a complex word is decomposable, the constituents «are accessed separately, and the procedural memory system is activated. Whole-words are retrieved as single units, and the declarative memory system is engaged» (Vannest, Polk and Lewis 2005: 69) ${ }^{1}$.

The research on the interfaces of language faculty provides a different conception of the relationship between lexicon and grammar. The lexicon is the repository not only of fixed expressions, but also of abstract particular phrases and word patterns: «words are in one corner of a multidimensional continuum of stored structures, maximally general rules are in another corner, and there are all sorts of phenomena of varying degrees of regularity in between» (Jackendoff 2009: 108).

In this paper we will take into account the investigations on semantic processing focused on (i) idiosyncratic vs compositional meanings, and on (ii) literal vs figurative readings of complex word meaning. Neurological research (cf. Stringaris et al. 2007, Mashal et al. 2008, Binder 2009) reveals that there are hemispheric differences in processing the (non) literal interpretation of idioms: (i) the processing of lexicalized and idiomatic meanings of idioms primarily engages the Left Hemisphere and the Right

\footnotetext{
${ }^{1}$ Vannest, Polk and Lewis 2005: 68 sustain that compositional processing of affixed words depends on the linguistic properties of the affix. We claim that the structure of the base, namely when [+Latinate], plays an important role in the decompositional or holistic access of the word (Rio-Torto, 2010).
} 
Lexical idiomaticity and word processing. António Fábregas, Elena Felíu, Josefa Martin García, José Pazó (ed.) 2012, Los limites de la morfología. Estudios oferecidos a Soledad Varela Ortega. Madrid, Universidad Autónoma de Madrid (col. Estudios 147): 397-412.

Hemisphere is mainly involved in the processing of literal meanings; (ii) the literal interpretation of an ambiguous structure is faster than its idiomatic interpretation; (iii) regular words show a more restricted extent of activation than irregular ones. The networking multimodal system of semantic processing is stressed by several authors (Devlin et al. 2003, among others). According to Binder et al. 2009: 2774, «The human semantic system $[\ldots]$ corresponds in large measure to the network of parietal, temporal, and prefrontal heteromodal association areas, which are greatly expanded in the human relative to the nonhuman primate brain» [...]. Evidence supports the subdivision of this network into posterior (temporal/parietal) and frontal components corresponding to storage and retrieval aspects of semantic processing».

\section{Compositionality and idiomaticity}

Idiomaticity and compositionality, as well as opacity and transparency, are two opposite poles of a scale in which the word's structure is represented. Idiomaticity is prevailingly associated to compounds and idioms. But other lexical units, such as affixes and derived words, present diacritic features and idiosyncratic meanings.

The perception of the compositionality/idiomaticity is ruled by several conditions, such as:

(i) the degree of exposure to the word.

(ii) the frequency of the lexical unit.

(iii) the degree of transparency/opacity and the (non) regularity of word's internal structure.

(iv) the pragmatic or cultural salience of what the word denotes.

(v) the linguistic explicit competence of the speaker (native/non native). 
Lexical idiomaticity and word processing. António Fábregas, Elena Felíu, Josefa Martin García, José Pazó (ed.) 2012, Los limites de la morfología. Estudios oferecidos a Soledad Varela Ortega. Madrid, Universidad Autónoma de Madrid (col. Estudios 147): 397-412.

Other factors, such as age (cf. Richardson et al. 2010), play a crucial role in lexical and semantic processing. As we have empirically observed, the perception of each word as (non) regular and/or (non)idiomatic, by contemporary university students of Portuguese L1, is governed by a wide range of parameters that recommend to modulate any generalization.

\subsection{Idiomaticity as a feature of derivation and compounding}

Compounding is often seen as a field of idiomaticity. Indeed, there are compounds whose meanings are compositional and transparent (3-7), while others have idiomatic meanings (12-19). But the same occurs with suffixed words, whose meanings are compositional (8-11) or idiomatic (20-24). The examples (1-2) display idiomatic meanings.

(1) revoltar 'to rebel, to break away from or rise against constituted authority', and not

'to come again', as re + voltar 'lit. again + to come' would mean.

(2) cachorro-quente 'hot dog', lit. [[young dog $\left.]_{\mathrm{N}}[\text { hot }]_{\mathrm{A}}\right]_{\mathrm{N}}$.

Cachorro-quente is a denomination of a specific type of sandwich containing a sausage served after cooking and garnished with mustard; the meaning of the whole is not deductible from the meanings of the parts. A speaker of Portuguese as non-native language doesn't understand its conventionalized meaning, unless previously exposed to it.

An alternative conception is sustained by those who distinguish compounds to idioms on the base of idiomaticity. According to Jackendoff (1997), compounds are lexical items of a productive pattern and with a predictable meaning, such as (we reproduce the examples of the author) AN acoustic guitar, Arabian horse, British accent, white flag, NN April shower, coffee break, jazz band, milk chocolate, skin 
Lexical idiomaticity and word processing. António Fábregas, Elena Felíu, Josefa Martin García, José Pazó (ed.) 2012, Los limites de la morfología. Estudios oferecidos a Soledad Varela Ortega. Madrid, Universidad Autónoma de Madrid (col. Estudios 147): 397-412.

cancer and odds-and-ends compounds (bed and breakfast, blackmail scheme, country and western band; nine-to-five work day). An idiom is a single lemma expressed by multiple lexical forms, which are combinations of independently listed items cooccurring redundantly, and whose meaning is not a function of the meanings of their constituents. Idioms can be: NP idioms (a breath of fresh air, point of view, son of a gun, wheel of fortune), PP idioms (right on the money), VP idioms (go for it, flying high).

On the contrary, we think that the semantic non compositionality characterizes idioms, many compounds as well as derivative words, so that it is not a feature that supports the distinction between nominal from phrasal compounds or idioms.

Compounds and derivative words may present greater or lesser semantic transparency, that is, their meaning may or may not correspond to the sum of the meanings of their constituents.

In (3-7) the compounds are semantically transparent:

(3) $[\mathrm{NA}]_{\mathrm{N}}$ cavalo árabe 'Arabian horse'.

(4) $[\mathrm{NN}]_{\mathrm{N}}$ saco-cama 'sleeping bag', lit. bag-bed.

(5) $[\mathrm{VN}]_{\mathrm{N}}$ abre-latas 'can-opener'.

(6) $[\mathrm{NA}]_{\mathrm{N}}$ guitarra acústica 'acoustic guitar'.

(7) $\left[[\mathrm{N}[\mathrm{PP}]]_{\mathrm{N}}\right.$ ponto de exclamação 'exclamation mark'(lit.mark of exclamation).

Similarly, many suffixed adjectives and nouns present no semantic opacity (8-11):

(8) canceroso 'cancerous'

(10) globalização 'globalisation'

(9) industrial 'industrial'

(11) terrorismo 'terrorism'

The opposite situation coexists with the aforementioned. The meaning of many compounds (12-19) is not predictable from the meaning of the parts. 